\title{
Diferenças individuais no processamento neural de frases em bilíngues do par linguístico português-inglês: um estudo com fMRI dos efeitos da compreensão leitora na ativação cerebral
}

\author{
Individual differences in the neural processing of sentences in Portuguese- \\ English bilinguals: an fMRI study of reading comprehension effects on brain \\ activation
}

\section{Cyntia Bailer}

Universidade Regional de Blumenau - FURB

\section{Lêda Maria Braga Tomitch}

Universidade Federal de Santa Catarina - UFSC

\begin{abstract}
Resumo: Este artigo apresenta um recorte de uma tese que objetivou investigar a resposta neuroanatômica de monolíngues e bilíngues ao processamento de frases escritas. Neste artigo, concentrou-se no objetivo de explorar em que medida diferenças individuais como proficiência na L2 e capacidade de memória de trabalho (CMT) modulam a ativação cerebral de 12 bilíngues tardios do par linguístico português brasileiro-inglês. Os resultados corroboraram a hipótese de que bilíngues mais proficientes engajariam a rota usual de compreensão (maior ativação na região temporal superior esquerda) enquanto bilíngues menos proficientes recorreriam a áreas no hemisfério direito (HD). Bilíngues com menor CMT, além de recrutar mais áreas do HD, recorreram a processos menos proficientes para compreender frases que bilíngues com maior CMT. O estudo acrescenta evidência à ideia de que o processamento de frases, as conexões entre as palavras na L2 e as representações semânticas da L1 se fortalecem conforme a proficiência na L2 aumenta.
\end{abstract}

Palavras-chave: Bilinguismo. Compreensão leitora. Ressonância magnética funcional. Proficiência. Capacidade de memória de trabalho.

Abstract: This article presents part of a dissertation that aimed at investigating monolingual and bilingual brains and their neuroanatomical response to the processing of written sentences. For this article, we concentrate on the objective of exploring whether individual differences, namely proficiency in the L2 and working memory capacity (WMC), modulate brain activation in 12 Brazilian Portuguese-English late bilinguals. Results corroborate the hypothesis that more proficient bilinguals would engage the usual route for comprehension (increased activation in the left superior temporal region) while lower proficient participants would resort to more rightlateralized areas. Lower WMC bilinguals, besides recruiting more right-lateralized areas, relied on less proficient processes to comprehend sentences than higher WMC bilinguals. The study adds evidence to the idea that the processing of sentences, the connections between words in the $\mathrm{L} 2$ and the semantic representations of the L1 strengthen as proficiency in the L2 increases.

Keywords: Bilingualism. Reading comprehension. Functional magnetic resonance imaging. Proficiency. Working memory capacity. 


\section{Introdução}

O bilinguismo é um fenômeno mundial. Conforme o mundo vai se interconectando cada vez mais, parece que o bilinguismo é "a regra e não a exceção" (BIALYSTOK et al., 2009, p. 89, tradução nossa). De acordo com Schwartz e Kroll (2006), bilíngues são aqueles que usam ativamente duas línguas com determinado grau de proficiência e são raramente proficientes no mesmo nível no uso das duas línguas. Grosjean (2012, p. 4, tradução nossa) define bilíngues como "aqueles que usam duas ou mais línguas (ou dialetos) em sua vida cotidiana". Ademais, os bilíngues não formam um grupo homogêneo, variam em diferentes dimensões: idade e forma de aquisição, nível de proficiência, quanto e em quais contextos usam as línguas.

Por causa da complexidade dos fatores envolvidos no bilinguismo, os mecanismos do cérebro bilíngue têm intrigado filósofos e pesquisadores por muito tempo. Estudos comportamentais e de neuroimagem têm sido conduzidos e mostram, muitas vezes, resultados conflitantes (GROSJEAN, 1998). Controvérsias emergem por esses estudos, muitas vezes, apresentarem diferentes definições do que é ser bilíngue, diferentes línguas, diferentes métodos e tarefas, bem como investigarem diferentes níveis no processamento da linguagem. Indivíduos aprendem e usam línguas por diferentes motivos, em diferentes domínios de suas vidas, em idades distintas, com pessoas diferentes. Os bilíngues podem estar no processo de aprender uma língua ou podem ter alcançado um nível de estabilidade. Também, seu repertório linguístico pode mudar ao longo do tempo. Apesar de todas essas variáveis em jogo, cada estudo contribui para o quebra-cabeça que é tentar compreender como os bilíngues dão conta de processar duas ou mais línguas no seu dia a dia.

Neste contexto, as diferenças individuais desempenham um papel crucial, já que a leitura é vista, neste estudo, como um processo cognitivo complexo que envolve a interação entre texto e leitor. O processamento da leitura varia de indivíduo para indivíduo por causa de uma ampla gama de fatores, tais como motivação, aptidão, capacidade de memória de trabalho (CMT), conhecimento prévio, entre outros.

Ainda que um considerável número de estudos comportamentais venha se dedicando a examinar os efeitos de diferenças individuais, como proficiência na segunda língua e capacidade de memória de trabalho, na compreensão leitora de bilíngues, poucos estudos de neuroimagem - técnica que permite observar diretamente o cérebro desempenhando funções em tempo real - comparam os efeitos dessas diferenças individuais nos processos de compreensão leitora no cérebro de bilíngues.

Este artigo apresenta um recorte de uma tese (BAILER, 2016) desenvolvida na Universidade Federal de Santa Catarina e na Carnegie Mellon University (Pittsburgh, PA, EUA). O estudo, de natureza transversal, quantitativa e exploratória, objetivou investigar cérebros de monolíngues do português-brasileiro e bilíngues do par linguístico português-brasileiro e inglês e sua resposta neuroanatômica ao processamento de frases escritas. Para os fins deste artigo, delimitou-se detalhar os resultados relativos ao objetivo de explorar em que medida diferenças individuais como proficiência na segunda língua (L2) e CMT modulam a ativação cerebral em bilíngues tardios. O estudo contou com 12 participantes bilíngues, o que pode ser considerado muito pouco se comparado ao número de participantes em estudos comportamentais. No entanto, tendo em mente o alto custo associado a experimentos com ressonância magnética funcional (fMRI), numa rápida busca na literatura, percebe-se que o tamanho da amostra deste estudo é similar a outros estudos com neuroimagem funcional. A hipótese relacionada ao objetivo é a de que a $\mathrm{L} 2$ e a CMT iriam modular a ativação em áreas cerebrais específicas: maiores efeitos do processamento semântico (WARTENBURGER et al., 2003) bem como o transbordo dinâmico da ativação para o hemisfério direito (PRAT et al., 2007).

No que segue, apresentamos uma breve revisão da literatura sobre o reconhecimento de palavras em leitura e as diferenças individuais no 
processamento da linguagem, os detalhes metodológicos do estudo, seguido pelos resultados e discussão, e por fim, as considerações finais.

\section{Brevíssima revisão da literatura}

O reconhecimento de palavras apresentadas visualmente baseia-se na correspondência entre as letras e as representações lexicais. $\mathrm{Na}$ leitura proficiente é quase impossível encontrar uma palavra visualmente e não acessar seu significado (PULVERMÜLLER, 2012). Há duas rotas paralelas de processamento para se chegar ao significado: a rota fonológica e a rota lexical. A primeira converte letras em sons da fala, enquanto a segunda dá acesso direto ao dicionário mental de significados (DEHAENE, 2009). Jobard e colegas (2011) chamam essas rotas de rota grafo-fonológica e de rota léxicosemântica. A primeira requer a ligação entre as unidades ortográficas com suas unidades fonológicas equivalentes; consequentemente, 0 acesso às palavras acontece através da recodificação do insumo grafêmico em fonêmico, antes do acesso ao seu significado. A segunda rota pareia as formas ortográficas das palavras inteiras às suas representações semânticas. Em línguas alfabéticas como o português e o inglês, os aprendizes iniciantes usam a rota fonológica como padrão até que sua familiaridade com a ortografia Ihes permita associar palavras a significados.

De acordo com Dehaene (2009, p. 38, tradução nossa), "todos os sistemas de escrita oscilam entre uma representação acurada do som e a rápida transmissão do significado". Ambas as rotas são automaticamente ativadas durante 0 reconhecimento de palavras escritas e agem em paralelo para mediar o acesso lexical. Palavras raras, novas, ou muito irregulares normalmente utilizam mais a rota fonológica, enquanto palavras frequentes utilizam a rota lexical.

A maioria dos estudos envolvendo bilíngues, revisados em Bailer (2016), controlaram a proficiência de seus participantes aplicando medidas subjetivas e/ou objetivas de proficiência, porém o foco dos estudos, em especial, os de neuroimagem, não era exclusivo na comparação entre níveis de proficiência ou na medida em que a proficiência afeta 0 processamento da linguagem. Meschyan e Hernandez (2006), no seu estudo com bilíngues do par linguístico espanhol-inglês, observaram que a língua menos praticada (no caso deles, o espanhol) requer maior esforço motor articulatório. Wartenburger e colegas (2003) investigaram dois grupos de bilíngues fluentes do par linguístico italiano-alemão: um grupo que aprendeu o alemão numa idade precoce e outro que aprendeu o alemão numa idade posterior. Eles concluíram que o nível de proficiência desempenha um papel no processamento semântico, enquanto a idade de aquisição, no processamento gramatical. No entanto, no conhecimento destas pesquisadoras, nenhum estudo publicou resultados sobre a comparação, dentro de uma amostra com pouca variabilidade, entre as áreas ativadas por bilíngues com um nível de proficiência mais baixo e bilíngues com um nível de proficiência mais alto.

Em relação à memória de trabalho, os pesquisadores concordam que a memória de trabalho desempenha um papel importante em todas as atividades cognitivas humanas (TOMITCH, 2003), já que é o sistema responsável por simultaneamente armazenar, manter e processar informação em curto prazo. Pesquisadores consideram a memória de trabalho como uma arena computacional onde os processos mentais acontecem em tempo real, e sua limitação se refere a quanto trabalho pode ser feito de cada vez, quanta CMT está disponível para ser dividida entre os processos simultâneos (DANEMAN; CARPENTER, 1980; JUST; CARPENTER, 1992; TOMITCH, 2003). Essa capacidade limitada difere entre indivíduos e tais diferenças são bons preditores de desempenho em tarefas cognitivas: indivíduos com maior CMT desempenham uma determinada tarefa melhor que indivíduos com menor CMT. Explica-se que quem tem maior CMT é capaz de manter e manipular na memória de trabalho mais informação relevante para completar tarefas 
complexas, e como resultado, demonstra desempenho melhor.

Estudos comportamentais relacionando CMT e desempenho linguístico na primeira língua (L1) são numerosos, e menos numerosos na L2. Correlações positivas foram encontradas em uma grande variedade de tarefas cognitivas de ordem superior, como compreensão auditiva e leitora, mas também em subprocessos como a construção da ideia geral, solução de ambiguidades, compreensão inferencial, uso de estratégias e estrutura textual, para mencionar alguns (BAILER, 2011).

Estudos de neuroimagem oferecem informações acerca de como a memória de trabalho é implementada no cérebro. Uma variedade de técnicas e tarefas revelou o córtex pré-frontal e áreas frontais e parietais como essenciais para a memória de trabalho (ALLOWAY; ALLOWAY, 2013; CABEZA; NYBERG, 2000). De acordo com Cabeza e Nyberg (2000), essas áreas são recrutadas conforme a natureza da tarefa e sua dificuldade. A CMT, medida pelo Reading Span Test (DANEMAN; CARPENTER, 1980), também é vista como estimativa de habilidade de leitura em estudos como 0 de Jobard e colaboradores (2011). Seus resultados mostraram que leitores com menor CMT ativaram mais áreas envolvidas no processamento visual, fonológico e semântico, inclusive áreas engajadas no processamento em série do input visual. De acordo com os autores, os participantes pareciam estar decompondo as palavras para acessá-las através da reconstrução grafo-fonológica em vez de uma rota ortográfica-semântica (DEHAENE, 2009). Já leitores com maior CMT recorreram menos a tais regiões: eles geralmente ativaram apenas as áreas implicadas no acesso direto ao significado da análise visual das palavras escritas.

Estudos como os de Prat e colegas (2007), Buchweitz e colaboradores (2009), e Prat e Just (2011) revelaram que leitores com maior CMT apresentam três propriedades-chave: "(1) maior eficiência (realizar a mesma tarefa com menor ativação); (2) maior adaptabilidade (mais modulação de ativação em função da variação na demanda da tarefa); e (3) sincronização mais alta (coordenação funcional maior)" (MASON; JUST, 2013, p. 154, tradução nossa).

Tendo essas informações em mente, apresentamos na sequência os detalhes metodológicos do estudo que objetivou investigar cérebros de monolíngues do português-brasileiro e bilíngues do par linguístico português-brasileiro e inglês e sua resposta neuroanatômica ao processamento de frases escritas (BAILER, 2016). Conforme já explicitado anteriormente, o foco deste artigo é sobre os dados coletados e os resultados analisados em relação aos bilíngues e em relação à medida que diferenças individuais como proficiência na L2 e CMT modulam a ativação cerebral.

\section{Método}

Esta seção descreve brevemente o método usado para investigar o processamento neural de frases em bilíngues e está organizada em cinco subseções. A primeira subseção trata do desenho do estudo, a segunda, dos participantes, a terceira, do paradigma experimental, a quarta, dos detalhes do fMRI, e a quinta, do processamento e análise dos dados de fMRI.

É importante destacar que os dados foram coletados enquanto a primeira autora deste artigo estava em seu doutorado sanduíche em uma universidade norte-americana, portanto, o estudo obteve aprovação do comitê de ética dessa instituição (Carnegie Mellon University Institutional Review Board - IRB protocol HS14-474).

\subsection{Desenho do estudo}

Os dados para o estudo foram coletados com os participantes em três sessões individuais. As duas primeiras envolviam os scans na máquina de fMRI, cada dia em uma língua e essa ordem foi contrabalançada. Seis participantes realizaram a sessão em português primeiro e seis, em inglês. Os seis que realizaram a primeira sessão em português, realizaram a sessão em inglês no segundo encontro, e vice-versa. Nessas duas primeiras sessões, a 
pesquisadora leu os termos de consentimento livre e esclarecido, e na sequência, cada participante respondeu a um questionário demográfico e a um teste de lateralidade, ambos prática padrão do laboratório em que o estudo foi conduzido. A pesquisadora leu e explicou as instruções da tarefa que o participante faria dentro da máquina e para garantir que não houvesse nenhuma dúvida, cada participante teve a oportunidade de praticar a tarefa num simulador, que é uma réplica de uma máquina de fMRI. Na sequência, cada participante foi levado à sala do scanner real para realizar a tarefa que levava uma hora. Após o término da tarefa, o participante era levado à uma outra sala para fazer o teste de reconhecimento, prática comum no laboratório para garantir que o participante prestou atenção às frases enquanto realizou a tarefa, e também responder ao questionário de impressões. A segunda sessão envolvia o mesmo procedimento, só que na outra língua, conforme recomendação de Grosjean (1998), para colocar o participante no modo monolíngue.

No terceiro e último encontro, cada participante desempenhou dois testes de CMT, o Reading Span Test, em inglês (DANEMAN; CARPENTER, 1980) e o Teste de Capacidade de Leitura, em português (TOMITCH, 2003, adaptado por BAILER, 2011), em ordem contrabalançada, um ao início da sessão, e o outro ao fim da sessão. Após cada teste, o participante respondeu o questionário retrospectivo. Também, cada participante respondeu uma versão adaptada da seção de leitura do TOEFL (Test of English as a Foreign Language - Educational Testing Service(C) para medir sua proficiência em leitura, além de um questionário sobre o contexto linguístico do participante. Os participantes receberam recompensa financeira ao fim de cada sessão, como é prática recorrente em pesquisas científicas nos EUA. Vale destacar que cada participante recebeu também uma imagem estrutural do seu cérebro e assim que o trabalho foi concluído, uma cópia eletrônica da tese desenvolvida.

\begin{tabular}{|l|}
\hline 1ạ sessão \\
\hline .Termo de consentimento; \\
\hline .Questionário demográfico e de lateralidade; \\
\hline . Instruções; \\
\hline . fMRI em uma língua (ordem contrabalançada); \\
\hline . Teste de reconhecimento; \\
\hline . Questionário de impressões. \\
\hline 2a sessão \\
\hline . Termo de consentimento; \\
\hline . Instruções; \\
\hline . fMRI na outra língua (ordem contrabalançada); \\
\hline . Teste de reconhecimento; \\
\hline . Questionário de impressões. \\
\hline 3a sessão \\
\hline . Teste de capacidade em Leitura (TCL) em uma \\
\hline língua; \\
\hline . Questionário sobre o teste; \\
\hline . Questionário sobre o contexto linguístico do \\
participante; \\
\hline . Teste de proficiência (versão adaptada da parte de \\
leitura do TOEFL); \\
\hline . TCL na outra língua; \\
\hline . Questionário sobre o teste. \\
\hline Tabela1: Desenho do estudo - participantes bilíngues \\
\hline
\end{tabular}

\subsection{Participantes}

Doze bilíngues tardios do par linguístico português brasileiro-inglês destros participaram do estudo. Na coleta de dados, possuíam idade média de 27 anos (intervalo de 20 a 32 anos), moravam nos EUA por um período médio de 2 anos (intervalo de 6 meses a 9 anos), vinham de uma diversidade de estados brasileiros (RS, SC, PR, SP, MG, CE e PE), e a idade média de início da aprendizagem de inglês era 12,9 anos (intervalo de 7 a 22 anos). Todos os doze eram altamente proficientes na língua inglesa na época da coleta de dados.

Quatro deles estavam matriculados em cursos de doutorado e quatro em cursos de graduação. Dos quatro restantes, dois já haviam concluído a graduação e dois, o doutorado. Oito dos doze já haviam realizado exames padronizados de proficiência na língua inglesa (TOEFL, IELTS) antes de entrar nos EUA e os quatro restantes tiveram sua 
proficiência atestada pela universidade brasileira de onde vêm. Para validar sua proficiência formalmente, os participantes tiveram de desempenhar uma versão adaptada do TOEFL. Os participantes obtiveram uma nota média de 8,53 (DP = 1,16; intervalo $=6,7-10)$. Nos questionários, revelaram o uso maior do inglês no seu dia a dia, mas também usavam o português (em menor escala).

\subsection{Paradigma experimental}

Os participantes leram 60 frases em inglês e suas versões equivalentes em português (ex.: The diplomat negotiated at the embassy / O diplomata negociou na embaixada) enquanto imagens cerebrais funcionais eram adquiridas em dois dias distintos. Conforme citado anteriormente, a língua de apresentação era contrabalançada: metade dos participantes fez primeiro a tarefa em inglês e metade em português. As frases foram apresentadas em branco num fundo preto. Cada frase era apresentada em partes, uma de cada vez, conforme a figura 1. Os participantes foram instruídos a ler cada parte da frase silenciosamente e a pensar sobre o significado de cada palavra, construindo uma representação mental vívida da frase. Após o ponto final, deveriam continuar a pensar sobre a frase e seus elementos. Quando o X aparecesse, deveriam se concentrar nele, relaxando e limpando a mente. Cada frase aparecia quatro vezes, de forma randomizada.

Figura 1: Representação esquemática do paradigma experimental

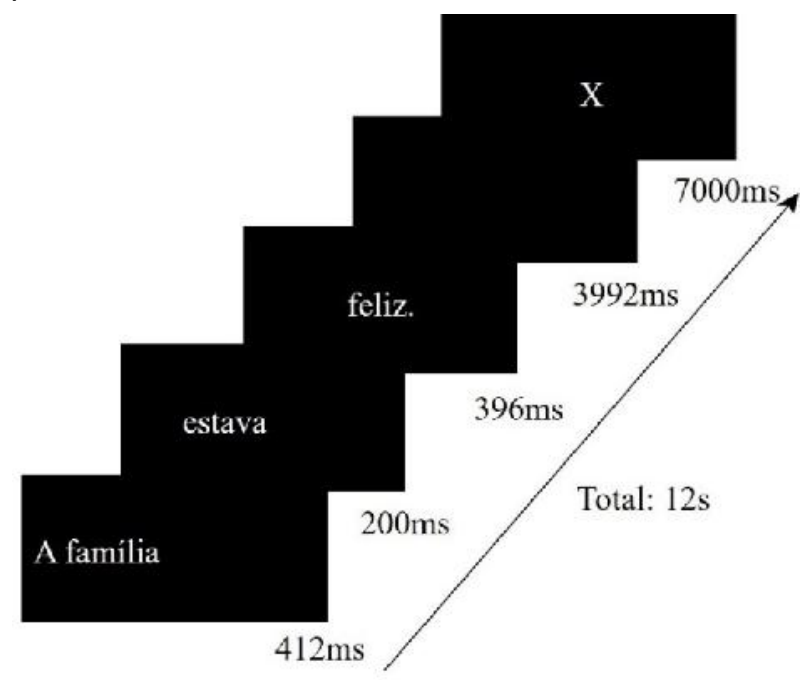

Após o fim de cada uma das duas primeiras sessões, os participantes realizaram o teste de reconhecimento para assegurar que prestaram total atenção às frases durante a tarefa no fMRI. Os resultados indicam que os participantes puderam processar as frases ativamente, pois puderam distinguir frases vistas e não vistas com uma acurácia média de $97 \%$.

Em relação aos testes de $\mathrm{CMT}$, os participantes exibiram uma média de 3,08 (DP = 0,92; intervalo $=2-5,5)$ em português e uma média de 3,25 $(D P=1,03$; intervalo $=2-5,5)$ em inglês. Conforme esperado, os resultados correlacionaram de forma forte e significativa $(r=0,879, p=0,000)$. Apesar da diferença nos resultados não ser estatisticamente significante, é interessante notar que a média mais alta é em inglês, a segunda língua. Levando em consideração o contexto em que os participantes viviam na época da coleta de dados, eles estavam imersos na cultura norte-americana: trabalhavam, estudavam, interagiam com a maioria das pessoas em inglês. O português era usado apenas para comunicação com a família e amigos no Brasil, brasileiros na cidade, ou para ler as notícias brasileiras online. Tais pontuações comparáveis parecem confirmar a proficiência dos nossos participantes na L2.

\subsection{Detalhes do fMRI}

Imagens funcionais foram adquiridas num Siemens Verio 3T no Scientific Imaging \& Brain Research Center (SIBR) da Carnegie Mellon University. Imagens foram geradas a partir de 16 fatias oblíquas-axiais de $5 \mathrm{~mm}$ de espessura (com 1 $\mathrm{mm}$ de diferença entre as fatias). A matriz de aquisição foi de 64 × 64 com 3,125 x 3,125 x 6 mm voxels, permitindo a obtenção de muitas observações do nível de ativação em cada voxel, gerando uma imagem de um amplo volume do cérebro em alta resolução. A apresentação das frases foi feita com o software CogLab, que sincroniza a aquisição de imagens com os estímulos visuais. Um projetor LCD projetou os estímulos visuais numa tela na parte de 
trás da máquina. Os participantes viram essa tela por meio de um sistema de espelho inclinado.

\subsection{Processamento e análise dos dados de fMRI}

Os dados foram analisados com o SPM8 (Wellcome Trust Centre for Neuroimaging, University College London). Os procedimentos padrão da análise de dados de fMRI foram feitos, como a correção do movimento de cabeça, a normalização para o modelo do Montreal Neurological Institute, e a regularização para reduzir ruído espacial. Para analisar se a proficiência na segunda língua e a CMT correlacionam com a ativação cerebral em bilíngues, imagens de contraste foram geradas (leitura > fixação) para cada participante em cada língua e a análise de segundo nível (entre participantes) foi feita nessas imagens de contraste com um teste t pareado com as diferenças individuais como regressores no modelo. Os testes estatísticos foram desempenhados pelo time do Center for Cognitive Brain Imaging (CCBI-Carnegie Mellon University). Conforme Amaro Jr. e Barker (2006, p. 220, tradução nossa), "um experimento com fMRI depende de técnicas e metodologias derivadas de diferentes áreas do conhecimento, tornando-o intrinsicamente multidisciplinar".

\section{Resultados e discussão}

Nesta seção, apresentamos os resultados, com o auxílio de figuras e tabelas, das análises estatísticas dos dados referentes aos participantes bilíngues e o impacto das diferenças individuais na compreensão de frases, seguidos da discussão desses dados em relação à literatura. A primeira subseção trata dos resultados e discussão relativos à proficiência na L2 e a segunda, à CMT.

\subsection{Proficiência}

A Figura 2 e a Tabela 2 apresentam os resultados em relação à proficiência na segunda língua $(T=4,14, p<0,001)$. Conforme os resultados revelam, quanto mais proficientes os participantes são em inglês, mais ativação eles demonstram na região temporal superior esquerda. Quanto menos proficientes, os participantes apresentam maior ativação na área frontal média direita, o caudado direito e o cerebelo esquerdo.

Figura 2: Áreas de ativação correlacionadas com a proficiência na segunda língua na leitura de bilíngues tardios
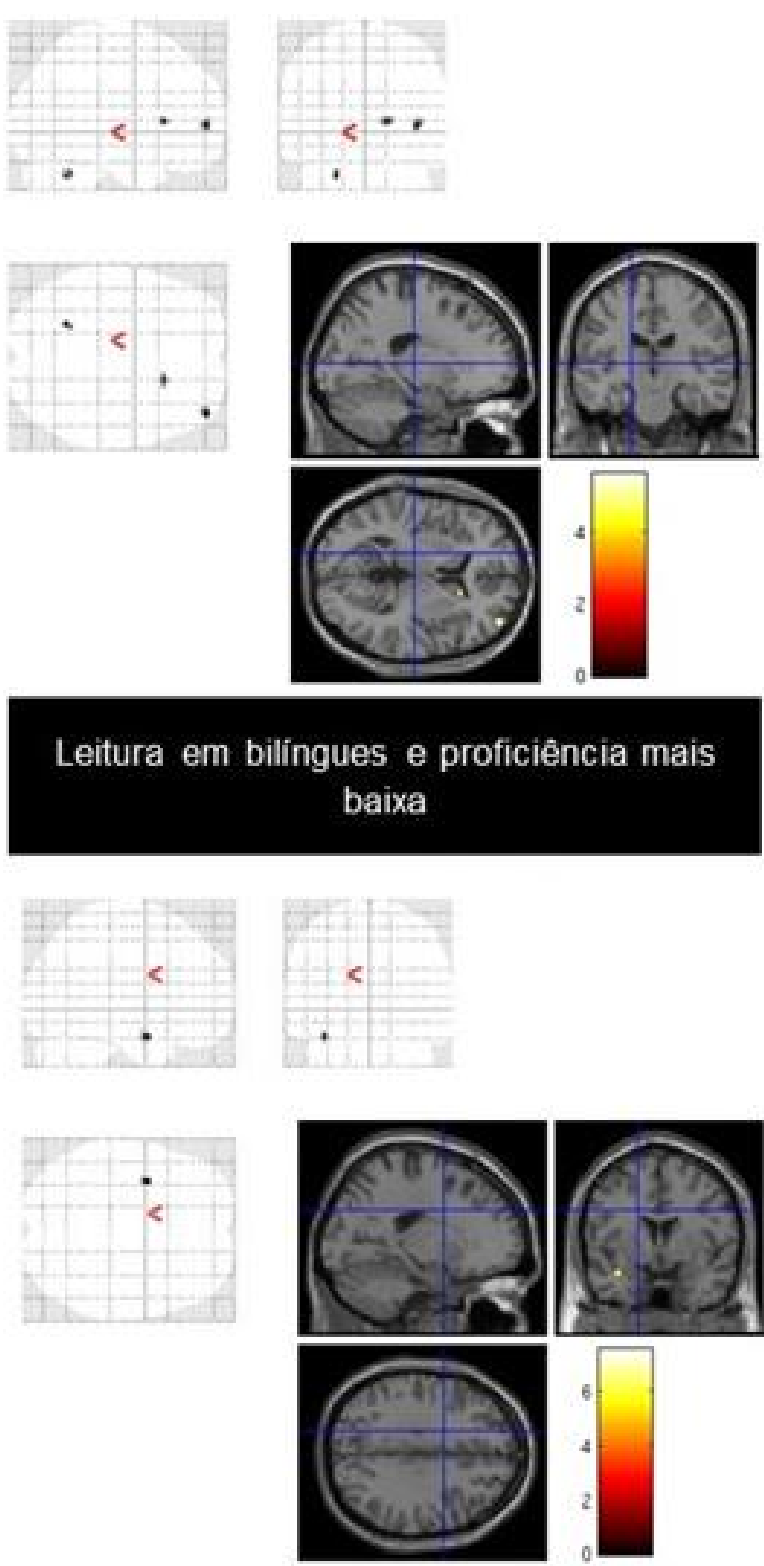

Leitura em bilingues e proficiência mais alta

(SPM8; $p<.001$, uncorrected; $T=4.14$; extent threshold voxels $=15$ ) 
Tabela 2: Áreas de ativação correlacionadas com a proficiência na segunda língua na leitura de bilíngues tardios

\begin{tabular}{|c|c|c|c|c|c|c|}
\hline \multicolumn{7}{|c|}{$\begin{array}{l}\text { Leitura de bilíngues em inglês com menor } \\
\text { proficiência }\end{array}$} \\
\hline \multirow{2}{*}{$\begin{array}{l}\text { Centróid } \\
\text { e e } \\
\text { ativação } \\
\text { adjacent } \\
\text { e }\end{array}$} & $\begin{array}{c}\text { Tamanh } \\
\text { o do } \\
\text { grupo }\end{array}$ & $\begin{array}{c}T \\
(12)\end{array}$ & $\begin{array}{l}\text { Área de } \\
\text { Brodman }\end{array}$ & \multicolumn{3}{|c|}{$\begin{array}{c}\text { Coordenada } \\
\text { MNI }\end{array}$} \\
\hline & & & & $x$ & $y$ & $z$ \\
\hline \multicolumn{7}{|l|}{ Frontal } \\
\hline $\begin{array}{l}\text { Área } \\
\text { frontal } \\
\text { média } \\
\text { direita }\end{array}$ & 25 & $\begin{array}{c}5,6 \\
1\end{array}$ & BA10 & $\begin{array}{l}4 \\
2\end{array}$ & $\begin{array}{l}5 \\
8\end{array}$ & 6 \\
\hline \multicolumn{7}{|c|}{ Subcortical } \\
\hline $\begin{array}{l}\text { Caudado } \\
\text { direito }\end{array}$ & 20 & $\begin{array}{c}5,1 \\
8\end{array}$ & & $\begin{array}{l}1 \\
6\end{array}$ & $\begin{array}{l}2 \\
4\end{array}$ & 8 \\
\hline \multicolumn{7}{|l|}{ Cerebelo } \\
\hline $\begin{array}{l}\text { Cerebelo } \\
\text { esquerdo }\end{array}$ & 15 & $\begin{array}{c}5,4 \\
0\end{array}$ & & $\begin{array}{l}- \\
2 \\
4\end{array}$ & $\begin{array}{l}- \\
5 \\
4\end{array}$ & $\begin{array}{l}- \\
3 \\
2\end{array}$ \\
\hline
\end{tabular}

\begin{tabular}{|c|c|c|c|c|c|c|}
\hline \multicolumn{7}{|c|}{$\begin{array}{l}\text { Leitura de bilíngues em inglês com maior } \\
\text { proficiência }\end{array}$} \\
\hline \multirow{2}{*}{$\begin{array}{l}\text { Centróid } \\
\text { e e } \\
\text { ativação } \\
\text { adjacent } \\
\text { e }\end{array}$} & $\begin{array}{c}\text { Tamanh } \\
\text { o do } \\
\text { grupo }\end{array}$ & $\begin{array}{c}T \\
(12)\end{array}$ & $\begin{array}{c}\text { Área de } \\
\text { Brodman } \\
n\end{array}$ & \multicolumn{3}{|c|}{$\begin{array}{c}\text { Coordenad } \\
\text { a MNI }\end{array}$} \\
\hline & & & & $x$ & $y$ & $z$ \\
\hline \multicolumn{7}{|l|}{ Temporal } \\
\hline \multicolumn{2}{|l|}{$\begin{array}{l}\text { Área } \\
\text { temporal } \\
\text { superior } \\
\text { esquerda }\end{array}$} & $\begin{array}{c}7,4 \\
9\end{array}$ & BA38 & - & 2 & \\
\hline \multicolumn{7}{|c|}{$\begin{array}{l}\text { Nota: Grupos de voxels significantes com } \mathrm{p}<0,001 \text {, não } \\
\text { corrigidos, } T=4,14 \text {. Contrastes entre bilíngues lendo em inglês } \\
\text { e sua proficiência na segunda língua. Os rótulos de região se } \\
\text { aplicam à toda a extensão do grupo com o pico máximo } \\
\text { designado pelo primeiro local citado. Valores T e coordenadas } \\
\text { MNI se referem ao voxel com pico de ativação em cada grupo. } \\
\text { Os rótulos são dados no sistema AAL (Automated Anatomical } \\
\text { Labeling System) conforme implementado no SPM8. }\end{array}$} \\
\hline
\end{tabular}

No presente estudo, os bilíngues mostraram um bom nível de proficiência em inglês ( $M=8,53$; DP = 1,16; intervalo = 6,7-10). O nível de proficiência em português não foi avaliado objetivamente, já que as pesquisadoras assumiram que todos os participantes eram proficientes em português, pois no questionário sobre o contexto linguístico, eles reportaram usar português todos os dias e também foram capazes de se comunicar fluentemente com a pesquisadora na coleta de dados.

Os achados mostram que uma maior proficiência na segunda língua está associada com ativação temporal superior esquerda. Abutalebi, Jubin e Perani (2001) revelaram que bilíngues precoces exibem ativação nas áreas clássicas da linguagem do hemisfério esquerdo: giros temporais superior e médio, giro angular, polo temporal e áreas frontais inferior e média. No caso de bilíngues tardios, os autores argumentam que o nível de proficiência molda a organização cortical das línguas, com a alta proficiência na segunda língua mostrando uma maior sobreposição com áreas corticais envolvidas no processamento da primeira língua. Ao comparar a ativação exibida pelos participantes bilíngues tardios deste estudo com maiores índices de proficiência, a área temporal superior esquerda (BA38), tradicionalmente associada com o polo temporal, emerge como o único ponto de ativação modulado pela proficiência. Esta área, de acordo com JungBeeman (2005, p. 515, tradução nossa), é parte da rede de integração semântica que "sustenta a interpretação de mensagens ao computar o grau de sobreposição semântica entre múltiplos campos semânticos". Tal rede que "detecta, elabora e refina relações semânticas de ordem superior" (p.515, tradução nossa) envolve o giro temporal superior anterior bilateral e o sulco temporal superior se estendendo até o giro temporal médio e o polo temporal. Logo, parece que bilíngues altamente proficientes estão empregando a rota usual de compreensão. De acordo com Ferstl (2007, p.85, tradução nossa), "os lobos temporais anteriores foram ativados em estudos ambos no nível do texto e da sentença quando a integração de palavras numa representação semântica era necessária”. Além disso, Perani e colegas (1998) encontraram maior ativação nos polos temporais em bilíngues altamente proficientes que em bilíngues menos proficientes. Assim, nós sugerimos que a alta proficiência desencadeia maior ativação em uma área normalmente envolvida na integração semântica.

Três grupos de voxels foram recrutados por bilíngues com menor proficiência: a área frontal média direita, o caudado direito e a área cerebelar esquerda. As coordenadas do agrupamento de voxels na parte frontal média estão associadas com a BA10, córtex pré-frontal, uma área cerebral tipicamente implicada 
no controle executivo. No estudo de Wartenburger e colegas (2003), bilíngues menos proficientes, comparados a bilíngues fluentes, mostraram ativação adicional na área de Broca e no giro frontal médio direito. Nosso achado do recrutamento da área média direita parece corroborar tal achado. O caudado está associado com o code-switching bilíngue, planejamento e seleção lexical (BIALYSTOK et al., 2009). Buchweitz e Prat (2013, p. 438, tradução nossa) explicam que

os gânglios basais, que são mais ricos em
dopamina e mais plásticos que o córtex,
parecem iniciar os mapeamentos dos
emparelhamentos estímulo-resposta,
enquanto o córtex pré-frontal pode finalmente
armazenar as representações abstratas de
tais mapeamentos.

A região pré-frontal e o estriado aparecem frequentemente ativados em estudos, conforme Prat (2011, p. 645, tradução nossa), e são recorrentes "quando os processos de compreensão de linguagem envolvem uma grande quantidade de controle cognitivo".

Em relação ao envolvimento do cerebelo, seu papel como coordenador da função motora é bem estabelecido na literatura, mas, de acordo com De Smet e colegas (2013), um número considerável de estudos têm estendido o papel do cerebelo para a modulação do processamento cognitivo, linguístico e afetivo, como no "aprendizado associativo não-motor, memória de trabalho, habilidades visuo-espaciais, fluência verbal, sintaxe, leitura e escrita" (p.339, tradução nossa). Cabeza e Nyberg (2000), em sua revisão de 275 estudos com PET e fMRI, descobriram que a ativação cerebelar pode estar relacionada ao nível de articulação na produção da fala e a processos de busca na memória. De Smet e colegas (2013) relatam que, em alguns estudos, pacientes com lesões apresentam fluência verbal reduzida, enquanto estudos de lateralidade com sujeitos não afetados por lesões descrevem a participação do cerebelo no processamento da linguagem como "contralateral à ativação do córtex cerebral, mesmo em condições de dominância diferente para a linguagem" (p.335, tradução nossa). Todavia, o papel específico do cerebelo na compreensão de leitura e sua ativação em situação de proficiência não tão alta ainda precisa ser melhor entendido.

Resumidamente, parece que nossos bilíngues não tão proficientes tiveram que recrutar os três conjuntos de voxels para ser capazes de realizar a tarefa de entender as frases. Apesar das frases serem simples e curtas, especula-se que os bilíngues menos proficientes recrutaram essas áreas quando tiveram de ser estratégicos para desempenhar os mesmos processos que os bilíngues mais proficientes executam naturalmente. Perani e colegas (1998, p. 1849, tradução nossa) argumentam que, em bilíngues com baixa proficiência, "áreas cerebrais múltiplas e variadas são recrutadas para lidar, na medida do possível, com as dimensões da L2 que são diferentes da L1". O presente estudo oferece suporte ao entendimento de que "as conexões entre palavras na L2 e as representações semânticas da primeira língua (L1) são fortalecidas conforme a proficiência na L2 aumenta" (BUCHWEITZ et al., 2012, p. 282, tradução nossa). Ademais, nós complementamos a citação ao incluir o processamento da L2 no nível da sentença.

\subsection{Capacidade de memória de trabalho}

A Figura 4 e a Tabela 2 apresentam os resultados em relação à CMT $(T=3,17, \mathrm{p}<0,005)$. Os resultados sugerem que quanto menor é a CMT dos participantes, mais ativação eles exibem em áreas frontais, como a área motora suplementar e o giro frontal inferior, na região lingual direita, e pequenos grupos de voxels nas seguintes áreas do hemisfério esquerdo: precuneus, tálamo e cúlmen. Por outro lado, quanto maior é a CMT dos participantes, mais ativação eles demonstram na área órbito-frontal superior esquerda, um grupo pequeno, mas estatisticamente significante. 
Figura 3: Áreas de ativação correlacionadas com a CMT na leitura de bilíngues tardios
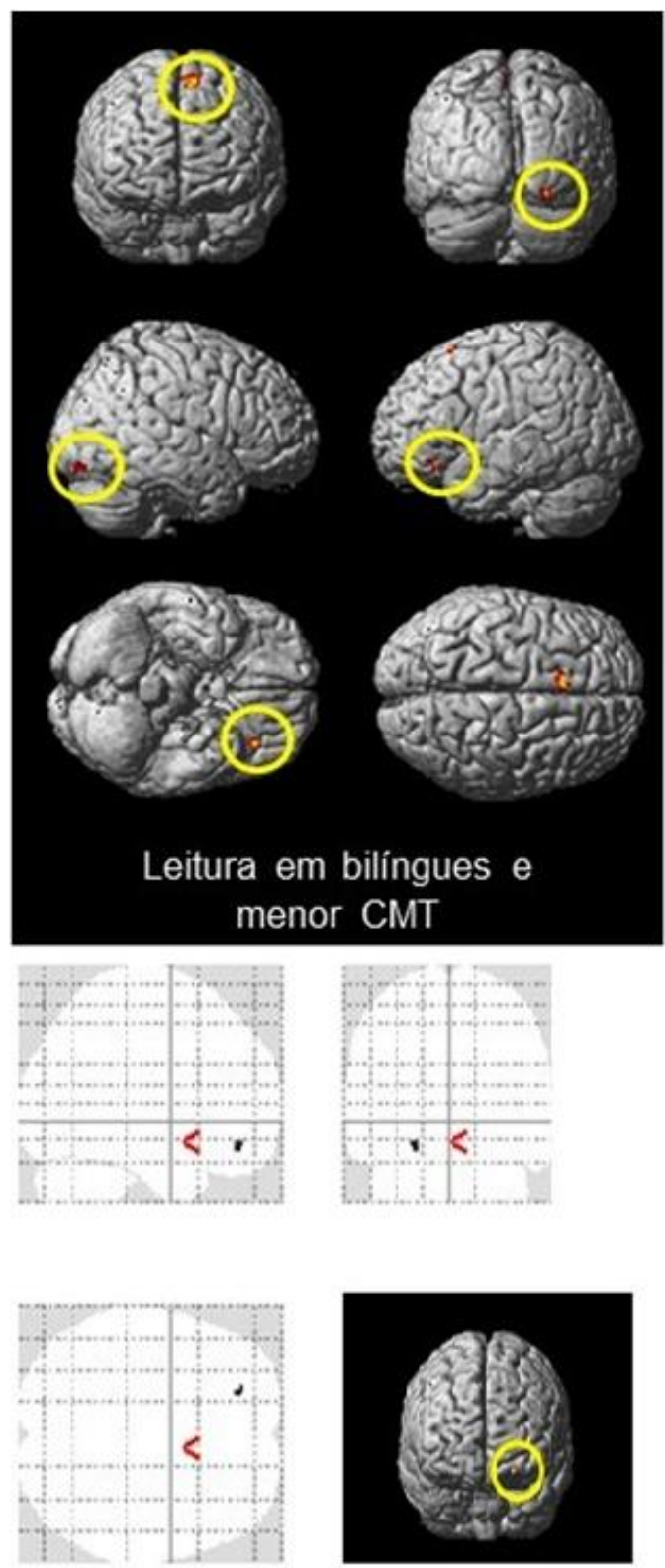

\section{Leitura em bilíngues $\mathrm{e}$} maior CMT

(SPM8; $p<.005$, uncorrected; $T=3.17$; extent threshold voxels $=5$ )
Tabela 3: Áreas de ativação correlacionadas com a CMT na leitura de bilíngues tardios

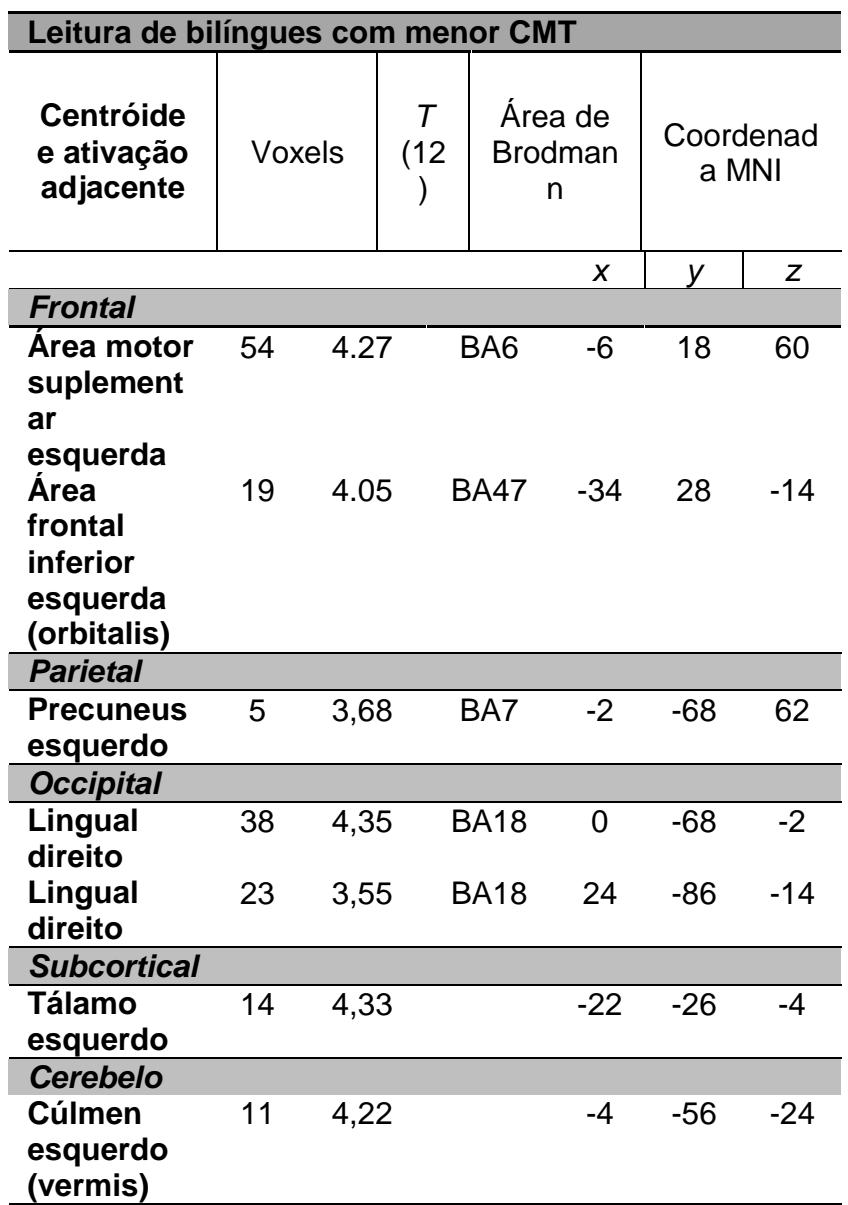

Leitura de bilíngues com maior CMT

\begin{tabular}{|c|c|c|c|c|c|c|}
\hline \multirow[t]{2}{*}{$\begin{array}{l}\text { Centróide } \\
\text { e ativação } \\
\text { adjacente }\end{array}$} & $\begin{array}{l}\text { Tamanh } \\
\text { o do } \\
\text { grupo } \\
\text { (voxels) }\end{array}$ & \multirow[t]{2}{*}{$\begin{array}{c}T \\
(12 \\
)\end{array}$} & \multicolumn{2}{|c|}{$\begin{array}{c}\text { Área de } \\
\text { Brodman } \\
n\end{array}$} & \multicolumn{2}{|c|}{$\begin{array}{c}\text { Coordenad } \\
\text { a MNI }\end{array}$} \\
\hline & & & & $x$ & $y$ & $Z$ \\
\hline \multicolumn{7}{|l|}{ Frontal } \\
\hline $\begin{array}{l}\text { Área } \\
\text { órbito- } \\
\text { frontal } \\
\text { superior } \\
\text { esquerda } \\
\text { (córtex } \\
\text { pré-frontal) }\end{array}$ & 3,8 & & BA11 & -22 & 44 & -14 \\
\hline
\end{tabular}

Nota: Grupos de voxels significantes com $p<0,005$, não corrigidos, $T=3,17$. Contrastes entre bilíngues lendo e sua CMT. Os rótulos de região se aplicam à toda a extensão do grupo com o pico máximo designado pelo primeiro local citado. Valores T e coordenadas MNI se referem ao voxel com pico de ativação em cada grupo. Os rótulos são dados no sistema AAL (Automated Anatomical Labeling System) conforme implementado no SPM8.

Em nosso estudo, bilíngues com maior CMT recrutaram um pequeno conjunto de voxels no córtex órbito-frontal superior esquerdo, parte do córtex préfrontal, que é tradicionalmente envolvido em funções da memória de trabalho. De acordo com Frey e 
Petrides (2000, p. 8723, tradução nossa), a "região órbito-frontal (área 11), que está principalmente conectada à região límbica temporal medial anterior e às áreas corticais pré-frontais laterais, está envolvida no processo de codificação de novas informações".

Já os bilíngues com menor CMT recrutaram uma rede de áreas nos dois hemisférios. Os achados parecem convergir com os resultados do estudo de Jobard e colegas (2011) realizado com monolíngues, que demonstra que leitores com menor CMT recrutam mais áreas envolvidas no processamento visual, fonológico e semântico. Eles encontraram maior ativação na área visual da forma da palavra, na região precentral esquerda, sulco temporal, planum temporale, área temporal média e a parte orbital do giro frontal inferior. Apesar de não coincidir totalmente, nossos resultados parecem sugerir que os leitores com menor CMT podem estar recorrendo a um acesso menos proficiente das palavras escritas ao usar regiões envolvidas no processamento fonológico que não são recrutadas por leitores com maior CMT. Também, nossos participantes estão recorrendo a áreas no hemisfério direito (transbordo dinâmico da ativação, PRAT et al., 2007). Nas palavras de Jobard e colegas (2011, p. 126, tradução nossa), "este padrão de resultados corrobora a hipótese de que leitores com desempenho mais baixo têm menos mapeamentos detalhados da ortografia ao significado, e, portanto, precisam reconstruir fonologicamente as palavras". De acordo com Prat e colegas (2007), nossos leitores com maior CMT não recorreram tanto às redes estratégicas e às áreas occipitais como os leitores com menor CMT fizeram.

Buchweitz e colegas (2009), no seu estudo com leitura e compreensão auditiva de bilíngues, observaram que leitores com menor CMT recorreram a estratégias diferentes para ler frases num formato de apresentação visual rápida em série em que uma palavra aparece de cada vez na tela. Leitores com maior CMT ativaram áreas cerebrais engajadas na repetição fonológica da informação (região angular esquerda, giros precentral e pós-central bem como o giro frontal inferior direito), enquanto leitores com menor CMT recrutaram mais voxels no hemisfério direito e no giro frontal médio esquerdo, normalmente associado com o controle executivo. Nosso estudo empregou um método de apresentação diferente, chamado de paradigma da janela que move (Moving window paradigm), em que uma parte da frase aparece de cada vez. Apesar dessa diferença, nossos resultados são similares no que tange ao fato de os leitores com menor CMT recrutarem mais áreas no hemisfério direito, no nosso caso, áreas associadas com o reconhecimento das palavras. Nossos resultados divergem no sentido de que a repetição fonológica das informações foi empregada pelos leitores com menor CMT enquanto nossos leitores com maior CMT apenas recrutaram o córtex préfrontal órbito-frontal.

Conforme esperado, nossos leitores bilíngues com menor CMT recrutaram mais áreas que os leitores com maior CMT, o que possivelmente reflete os processos mais eficientes que os leitores com maior CMT exibem (PRAT; MASON; JUST, 2011). Bialystok e colaboradores (2009, p. 104, tradução nossa) postulam que a "vantagem bilíngue deve ser encontrada na memória de trabalho". Como os bilíngues precisam constantemente administrar dois sistemas de língua ativos e manipular atenção a um ou ao outro, e às vezes, aos dois, durante o uso da linguagem, acredita-se que devem ter um controle executivo aprimorado em uma variedade de tarefas (GROSJEAN, 2012; TREVISOL; TOMITCH, 2017). Logo, nossos leitores bilíngues com maior CMT exibem eficiência maior (PRAT; MASON; JUST, 2011) no desempenho em leitura.

\section{Considerações finais}

Para resumir, a resposta do nosso objetivo relacionado à medida que diferenças individuais, proficiência na L2 e CMT, modulam a ativação cerebral em bilíngues tardios é consistente com a hipótese lançada. Nossos achados revelam que bilíngues mais proficientes engajaram a rota usual de compreensão (ao demonstrarem maior ativação na região temporal superior esquerda) enquanto bilíngues menos proficientes tiveram de recorrer a 
mais áreas no hemisfério direito (WARTENBURGER et al., 2003; PRAT; MASON; JUST, 2011). Os bilíngues mais proficientes empregaram a rota usual de compreensão ao integrar as palavras conforme iam aparecendo numa representação semântica (FERSTL, 2007). Por sua vez, bilíngues menos proficientes engajaram a maioria das áreas no hemisfério direito (transbordo dinâmico da ativação) para desempenhar os mesmos processos que os bilíngues mais proficientes executam naturalmente (PERANI et al., 1998). O estudo acrescenta evidência à ideia de que o processamento de frases, as conexões entre as palavras na $\mathrm{L} 2 \mathrm{e}$ as representações semânticas da L1 se fortalecem conforme a proficiência na L2 aumenta.

Os achados de CMT sugerem que uma menor CMT modula atividade num conjunto de áreas bilaterais envolvidas no processamento visual, fonológico e semântico (JOBARD et al., 2011). Ao recrutar mais áreas do hemisfério direito, os leitores bilíngues com menor CMT podem estar recorrendo a processos menos proficientes para decodificar o input escrito. Já os leitores bilíngues com menor CMT recorreram mais a áreas de processamento semântico e fonológico, às quais leitores com maior CMT não recorreram. Por sua vez, leitores bilíngues com maior CMT demonstraram processos mais eficientes ao recrutar uma região frontal esquerda tradicionalmente associada à codificação de novas informações (FREY; PETRIDES, 2000).

Devido à natureza do estudo, os resultados devem ser vistos mais como sugestivos que conclusivos. Apesar do fato de ter sido orientado pela literatura, o estudo sofreu diversas limitações, como o tamanho da amostra e a baixa variabilidade de diferenças individuais. Uma possibilidade seria ter um grupo de bilíngues precoces e/ou um grupo de leitores com baixa proficiência para comparar com o grupo de bilíngues tardios proficientes. Todavia, é essencial destacar que este estudo conseguiu controlar de forma satisfatória a idade de aquisição da L2 e a proficiência com uma avaliação transversal da proficiência que os participantes demonstravam na oportunidade da coleta de dados.
Para concluir, "o bilíngue é um todo integrado que não pode ser facilmente decomposto em duas partes distintas, [...] ele não é uma soma de dois (ou mais) monolíngues completos ou incompletos, ele/a tem uma configuração linguística específica e única" (GROSJEAN, 2012, p. 75, tradução nossa). Como os bilíngues são uma população híbrida, muitos outros fatores além dos aqui estudados e reportados podem estar envolvidos na modulação da atividade neural. Destarte, o bilinguismo e o impacto das diferenças individuais constituem-se como uma área fértil para estudos.

\section{Agradecimentos}

As autoras aproveitam a oportunidade para agradecer ao Dr. Marcel Just pela acolhida da primeira autora na Carnegie Mellon University no período 2014-2015, por todo o suporte do Center for Cognitive Brain Imaging. Sem o envolvimento da equipe do laboratório e o apoio da CAPES e da UFSC, este estudo não teria sido possível.

\section{Referências}

ABUTALEBI, Jubin; CAPPA, Stefano F.; PERANI, Daniela. The bilingual brain as revealed by functional neuroimaging. Bilingualism: Language and Cognition, v. 4, n. 2, p. 179-190, 2001.

ALLOWAY, Tracy; ALLOWAY, Ross. The Working Memory Advantage. New York: Simon \& Schuster, 2013. 352 p.

AMARO JR., Edson; BARKER, Gareth J. Study design in fMRI: Basic principles. Brain and Cognition, v. 60, p. 220-232, 2006.

BAILER, Cyntia. The neural processing of sentences in bilinguals and monolinguals: an fMRI study of Portuguese-English bilinguals and Portuguese monolinguals reading comprehension effects on brain activation. 2016. $341 \mathrm{f}$. Tese (Doutorado em Estudos da Linguagem-Inglês) - Curso de PósGraduação em Inglês, Universidade Federal de Santa Catarina, Florianópolis, 19 fev 2016.

BAILER, Cyntia. Working memory capacity and attention to form and meaning in EFL reading. 2011. 181 f. Dissertação (Mestrado em Letras: Inglês e Literatura Correspondente) - Curso de Pós-Graduação em Inglês, Universidade Federal de Santa Catarina, Florianópolis, 29 nov 2011. 
BIALYSTOK, Ellen et al. Bilingual Minds. Psychological Science in the Public Interest, v. 10, n. 3, p. 89-129, 2009.

BUCHWEITZ, Augusto et al. Brain activation for reading and listening comprehension: An fMRI study of modality effects and individual differences in language comprehension. Psychology \& Neuroscience, v. 2, n. 2, p. 111-123, 2009.

BUCHWEITZ, Augusto et al. Identifying bilingual semantic neural representations across languages. Brain \& Language, v. 120, p. 282-289, 2012

BUCHWEITZ, Augusto; PRAT, Chantel. The bilingual brain: Flexibility and control in the human cortex. Physics of Life Reviews, v. 10, p. 428-443, 2013.

CABEZA, Roberto; NYBERG, Lars. Imaging cognition II: An empirical review of 275 PET and fMRI studies. Journal of Cognitive Neuroscience, v. 12, n. 1, p. $1-47,2000$.

DANEMAN, Meredyth; CARPENTER, Patricia A. Individual differences in working memory and reading. Journal of Verbal Learning and Verbal Behavior, v. 19, n. 4, p. 450-466, 1980.

DE SMET, Hyo J. et al. The cerebellum: Its role in language and related cognitive and affective functions. Brain \& Language, v. 127, p. 334-342, 2013.

DEHAENE, Stanislas. Reading in the brain. USA: Viking, 2009. $400 \mathrm{p}$.

FERSTL, Evelyn C. The Functional Neuroanatomy of Text Comprehension: What's the Story So Far? In: SCHMALHOFER, F.; PERFETTI, C.A (Org.). Higher Level Language Processes in the Brain. New York: Psychology Press Taylor \& Francis Group, 2007, p. 53-102.

FREY, Stephen; PETRIDES, Michael. Orbitofrontal cortex: A key prefrontal region for encoding information. PNAS, v. 97, n. 15, p. 8723-8727, jul. 2000.

GROSJEAN, François. Bilingual: Life and Reality. Cambridge, MA, USA: Harvard University Press, 2012. 304 p.

GROSJEAN, François. Studying bilinguals: Methodological and conceptual issues. Bilingualism: Language and Cognition, v. 1, p. 131-149, 1998.

JOBARD, G. et al. The weight of skill: Interindividual variability of reading related brain activation patterns in fluent readers. Journal of Neurolinguistics, v. 24, p. 113-132, 2011.

JUNG-BEEMAN, Mark. Bilateral brain processes for comprehending natural language. Trends in Cognitive Sciences, v. 9, n. 11, p. 512-518, 2005.
JUST, Marcel A.; CARPENTER, Patricia A. A capacity theory of comprehension: Individual differences in working memory. Psychological Review, v. 99, p. 122-149, 1992.

MASON, Robert A.; JUST, Marcel A. Identifying component discourse processing from their fMRI time course signatures. In: BRITT, M.A.; GOLDMAN, S.R.; ROUET, J-F. (Org.). Identifying Component Discourse Processes Reading-from works to multiple texts. New York: Routledge, 2013, p. 147-159.

MESCHYAN, Gayane; HERNANDEZ, Arturo E. Impact of language proficiency and orthographic transparency on bilingual word reading: An fMRI investigation. Neurolmage, v. 29, p. 1135-1140, 2006.

PERANI, Daniela et al. The bilingual brain: Proficiency and age of acquisition of the second language. Brain, v. 121, p. 1841-1852, 1998.

PRAT, Chantel S. The Brain Basis of Individual Differences in Language Comprehension Abilities. Language and Linguistics Compass, v. 5, n. 9, p. 635-649, 2011.

PRAT, Chantel S.; JUST, Marcel A. Exploring the neural dynamics underpinning individual differences in sentence comprehension. Cerebral Cortex, v. 21, n. 8, p. 1747-1760, 2011.

PRAT, Chantel S.; KELLER, Timothy A.; JUST, Marcel A. Individual Differences in Sentence Comprehension: A Functional Magnetic Resonance Imaging Investigation of Syntactic and Lexical Processing Demands. Journal of Cognitive Neuroscience, v. 19, n. 12, p. 1950-1963, 2007.

PRAT, Chantel S.; MASON, Robert A.; JUST, Marcel A. Individual differences in the neural basis of causal inferencing. Brain \& Language, v. 116, p. 1 13, 2011.

PULVERMÜLLER, Friedemann. Meaning and the brain: The neurosemantics of referential, interactive, and combinatorial knowledge. Journal of Neurolinguistics, v. 25, p. 423-459, 2012.

SCHWARTZ, Ana I.; KROLL, Judith F. Language Processing in Bilingual Speakers. In: TRAXLER, M.; GERNSBACHER, M. (Org.). Handbook of Psycholinguistics (2nd ed.). San Diego, CA, USA: Elsevier Academic Press, 2006, p. 967-999.

TOMITCH, Lêda M.B. (2003). Reading: text organization perception and working memory capacity. Florianópolis, SC: PGI/UFSC, ARES Advanced Research in English Series, 2003. 227 p.

TREVISOL, Juliane R.; TOMITCH, Lêda M.B. The relationship between bilingualism and working memory: a review. Revista do GELNE, Natal/RN, v. 19, n. 1, p. 39-51, jan-jun.2017. 
WARTENBURGER, Isabell et al. Early Setting of Grammatical Processing in the Bilingual Brain. Neuron, 37, 159-170, 2003.

\section{COMO CITAR ESSE ARTIGO}

BAILER, Cyntia; TOMITCH, Lêda Maria Braga. Diferenças individuais no processamento neural de frases em bilíngues do par linguístico português-inglês: um estudo com fMRI dos efeitos da compreensão leitora na ativação cerebral. Signo, Santa Cruz do Sul, v. 42, n. 75, dez. 2017. ISSN 1982-2014. Disponível em: $<$ https://online.unisc.br/seer/index.php/signo/article/view/9823>. Acesso em: doi: http://dx.doi.org/10.17058/signo.v42i75.9823. 